\title{
LA AUTONOMIA DE MUNICIPIOS Y PROVINCIAS EN LA NUEVA LEY BASICA DEL REGIMEN LOCAL
}

$352.072 .1(094.4)$

\author{
por \\ Jesús Leguina Villa \\ Catedrático de Derecho Administrativo
}

Desde los orígenes mismos del Estado contemporáneo, las colectividades locales han venido siendo sin remedio el pariente pobre y enfermo de la familia de Administraciones públicas españolas. Los casi dos siglos de centralización —en las diferentes versiones alumbradas tanto por el liberalismo de signo moderado o de tendencia progresista, como por las dictaduras ultraconservadorasno han sido otra cosa para los Municipios y Provincias que, a salvo fugaces balones de oxígeno, un proceso imparable de anquilosamiento de sus instituciones representativas de autogobierno y de depauperización de sus finanzas y competencias. Se trata de un hecho histórico tan conocido que no precisa ahora de mayores descripciones y comentarios. Pero es al propio tiempo un fenómeno que, quiérase o no, proyecta todos sus perniciosos efectos sobre nuestro presente.

Estamos, en efecto, demasiado acostumbrados a la insignificancia de nuestros Entes locales frente al todopoderoso Estado; nuestros hábitos mentales, la forma que tenemos de ver las cosas -la cosa pública, en este caso-, están tan condicionados por la centralización uniformadora, heredada del pasado remoto y reciente, que 
nos resulta casi imposible imaginar un sistema de organización territorial del poder político y de las estructuras administrativas en el que los Entes locales dejen de ser simples apéndices marginales y subordinados del aparato del Estado central o, a partir de ahora, de las emergentes Comunidades Autónomas, para convertirse también, junto a estas últimas, en piezas capitales del nuevo Estado autonómico. Difícil imaginar ciertamente que, más allá de la retórica coyuntural de algunos políticos y más acá de utopismos panmunicipalistas de ciertos ingenieros sociales de salón, los Entes locales puedan ocupar algún día el lugar destacado que les corresponde en la gestión de los asuntos ciudadanos.

$\mathrm{Y}$, sin embargo, éste es el reto y ésta es la tarea para la que han sido emplazadas las Entidades locales por «nuestra querida Constitución», como es invocada la Carta Magna española en el sobresaliente Preámbulo de la reciente Ley Reguladora de las Bases del Régimen local de 2 de abril de 1985 (en adelante, LBRL), pieza doctrinal de primera calidad que contiene muy atinadas reflexiones sobre la conformación de nuestro pretérito Régimen local, pero a la que cabe objetar, no obstante, que omita inesperadamente toda referencia a las últimas cuatro décadas del franquismo.

La Constitución de 1978 ha instaurado, en efecto, un modelo de Estado plural o compuesto cuyas estructuras territoriales - las Comunidades Autónomas, las Provincias y los Municipios-gozan todas ellas de autonomía para la gestión de sus respectivos intereses. Se ha pasado así de un sistema de poder concentrado en las instancias del Estado central a otro de policentrismo político y administrativo que se caracteriza, como subraya el citado Preámbulo de la Ley, por la esencial igualdad posicional de todas las Administraciones territoriales en el ejercicio de sus competencias y en la gestión de sus respectivos ámbitos de intereses públicos. Policentrismo y autonomía de las diversas piezas de la organización política y administrativa que obligan a llevar a cabo, por decirlo con palabras del Tribunal Constitucional en su famosa sentencia de las Diputaciones catalanas de 28 de julio de 1981, «una redistribución de competencias en función del respectivo interés entre las diversas Entidades, para que el modelo de Estado configurado por la Constitución tenga efectividad práctica».

Es aquí justamente, en el terreno de la efectividad práctica del modelo autonómico, donde Municipios y Provincias han de encontrar los mayores obstáculos, y no sólo por la ya aludida tradición 
de prepotencia estatocéntrica, tan insensible y resistente al cambio operado por la norma fundamental, sino también, y muy particularmente, porque en ese obligado proceso de redistribución competencial exigido por el nuevo modelo de Estado, las Corporaciones locales se enfrentan, además, con unos formidables competidores: las Comunidades Autónomas.

Conviene recordar, en efecto, que, no obstante la esencial igualdad posicional de los aparatos administrativos de todas las colectividades territoriales, la autonomía de las Nacionalidades y Regiones es, de un lado, cualitativamente superior a la de los Entes locales, superioridad que se manifiesta principalmente en la potestad legiferante que la Constitución y los Estatutos de Autonomía les reconocen: autonomía política, pues, frente a autonomía administrativa de Provincias, Islas y Municipios. Y, de otro lado, hay que tener en cuenta que las competencias asumidas por las Comunidades Autónomas son las que les reconocen y atribuyen asimismo la propia Constitución y los Estatutos de Autonomía, mientras que el acervo competencial de las Entidades locales, definidor de su autonomía, queda a disposición de la voluntad, potencialmente cambiante, del legislador ordinario, con el solo límite del núcleo esencial de las instituciones locales, esto es, de la imagen que de tales instituciones tiene la sociedad española de nuestros días.

En suma: la Constitución garantiza a unas y otras - Comunida- : des Autónomas y Corporaciones locales- autonomía para administrar sus propios asuntos, pero el reparto de competencias que aquélla comporta - para que tenga "efectividad práctica» el nuevo sistema de organización territorial del Estado- ha sido ya predeterminado en el propio bloque de la constitucionalidad sólo en lo que concierne a las Comunidades Autónomas: éstas saben ya cuántas y cuáles son las competencias que pueden ejercer como propias desde la entrada en vigor de los Estatutos y la culminación del proceso de transferencias de servicios. Por el contrario, las Entidades locales han de esperar a que el legislador ordinario -estatal o autonómico - vaya definiendo paulatinamente el alcance de su autonomía caso por caso, es decir, en cada uno de los sectores, de las materias o de las actividades en que estén involucrados intereses locales/ $\mathrm{Y}$ ello porque, como ha declarado el Tribunal Constitucional en la sentencia antes citada, la autonomía que la norma fundamental reconoce a Municipios y Provincias no asegura tanto «un contenido concreto o un ámbito competencial determinado y 
fijado de una vez por todas», sino que debe ser entendida más bien como una disponibilidad o un derecho general de aquellas colectividades a participar con su propia organización «en el gobierno y administración de cuantos asuntos les atañen, graduándose la intensidad de esta participación en función de la relación entre intereses locales y supralocales dentro de tales asuntos o materias".

$\mathrm{Al}$ romperse el estrecho marco de los asuntos estrictamente locales y superarse, en consecuencia, el añejo binomio «intereses locales exclusivos-competencias locales exclusivas», al cual se ceñía tradicionalmente el autogobierno local, la autonomía de los Municipios (y de las Islas y Provincias) gana, sin duda, en potencialidad, flexibilidad y dinamismo, pero no deja de acusar al tiempo cierta fragilidad constitutiva, pues, en definitiva, su mayor o menor alcance en cada sector de intervención administrativa depende pura y simplemente de la voluntad de la Ley.

Reducir esa inevitable fragilidad de la autonomía local y disponer mecanismos técnicos que materialicen la presencia de las Administraciones locales en todos los asuntos que, en uno $u$ otro grado, tengan relevancia para las comunidades vecinales y provinciales son dos de los propósitos esenciales de la nueva Ley Básica del Régimen local. Objetivos nada sencillos de alcanzar, desde luego, y que, a mi juicio, sólo limitadamente quedan cubiertos.

Conforme a la nueva concepción de la autonomía local, la LBRL reconoce efectivamente a los Entes locales (Municipios, Provincias e Islas) «su derecho a intervenir en cuantos asuntos afecten directamente al círculo de sus intereses», pero el aseguramiento concreto de tal derecho de autogobierno local es misión en cada caso de «la legislación del Estado y de las Comunidades Autónomas, reguladoras de los distintos sectores de acción pública», las cuales, al fijar el régimen jurídico de cada materia, habrán de atribuir a los Entes locales «las competencias que proceda en atención a las características de la actividad pública de que se trate y a la capacidad de gestión de la Entidad local" (art. 2, 1). Asimismo, en aquellas materias cuya regulación legal esté constitucionalmente compartida entre el Estado, titular de la potestad legislativa básica, y las Comunidades Autónomas, que aprueban la legislación complementaria o de desarrollo, la LBRL dispone que es función de las Leyes básicas del Estado - y no de las Leyes autonómicas de desarrollo- determinar las competencias "que, en todo caso, deban corresponder a los Entes locales en la materia que regulen» (art. 2, 2). 
La efectividad de la autonomía local se instrumenta, por tanto, en un mandato que el legislador estatal del Régimen local dirige al legislador sectorial, mandato cuya fuerza obligatoria para este último pretende basarse en la sigular posición que ocupa la Ley Básica del Régimen local en su condición de «norma institucional de los Entes locales", que desarrolla en exclusiva "la garantía constitucional de la autonomía local» (Preámbulo de la LBRL), Ley que, como ha observado Parejo, por desempeñar en el ámbito local un papel análogo al que juegan los Estatutos para las Comunidades Autónomas, estaría dotada, según esta opinión, de una reduplicada vis normativa.

No parece fácil evitar ni remediar, sin embargo, los posibles incumplimientos de ese deber de respeto de la autonomía local por parte del futuro legislador ordinario. Por dos razones: primera, porque la LBRL, pese a todo su valor político y su insustituible papel en la ordenación institucional de la Administración en su conjunto, no es a la postre más que una simple Ley ordinaria que carece de plusvalor alguno frente a las demás Leyes ordinarias de carácter sectorial (como, sin embargo, sí lo tienen los Estatutos de Autonomía frente a todas las Leyes, estatales o autonómicas), y segunda, porque la Constitución no permite a las Corporaciones locales acudir directamente ante el Tribunal Constitucional para impugnar las Leyes que vulneren su autonomía. Además de contemplar su participación en los instrumentos de planificación estatales y autonómicos, las dos únicas posibilidades que la propia LBRL brinda a los Entes locales, en defensa de su autonomía amenazada o desconocida, consisten en hacer oir su voz inicialmente en el seno de la Comisión Nacional de Administración Local cuando ésta haya de informar los proyectos de Ley y de Reglamentos estatales (no los autonómicos) que afecten a dicha autonomía y, en último término, en solicitar por sí mismos (como permite la propia Constitución) o a través de su representación en la citada Comisión (como prevé la LBRL) que los órganos constitucionalmente legitimados para ello impugnen ante la jurisdicción constitucional las Leyes del Estado o de las Comunidades Autónomas que se estimen lesivas para la autonomía local, garantizada en los artículos 137, 140 y 141 de la Constitución.

De otro lado, no cabe desconocer que, sin perjuicio de su esencial corrección y de su cabal adecuación a la realidad de una Admi- 
nistración local en estrecha simbiosis con el entorno social, económico y político general, este entendimiento de la autonomía local como derecho de participación in genere en todos los asuntos que involucren intereses locales adolece de cierto nivel de abstracción y sitúa a las Corporaciones locales en una posición institucional de relativa indefinición competencial dentro del sistema general de organizaciones administrativas. Por ello, la nueva LBRL, sin abandonar el plano de la abstracción en la delimitación de la autonomía local, ha querido descender al propio tiempo a un terreno más concreto, señalando cuáles son las tareas y funciones propias y específicas de las colectividades locales.

Pero en este proceso de tránsito de lo abstracto (derecho de participación) a lo concreto (derecho a la titularidad de ciertos servicios y actividades), la nueva Ley marca una diferencia cualitativa entre los Municipios, de un lado, y las Provincias e Islas, de otro. Dada su condición de Entes territoriales, la LBRL reconoce a todas las Corporaciones locales sin distinción la titularidad de un haz de potestades públicas (reglamentaria, tributaria, planificadora, expropiatoria, etc.), inherentes al concepto mismo de autonomía, recogiendo aquí también las aportaciones doctrinales más recientes y la jurisprudencia del Tribunal Constitucional ("para el ejercicio de esa participación en el gobierno y administración de cuanto les atane, los órganos representativos de la comunidad local han de estar dotados de las potestades sin las que ninguna actuación autónoma es posible", STC 28 de julio de 1981). Pero a partir de ahí, el alcance y la significación del autogobierno local son muy distintos en cada uno de estos dos escalones de la organización territorial.

Por de pronto, al Municipio la Ley le reconoce una aptitud o vocación general, o con palabras del Preámbulo, una «capacidad potencialmente universal», para "promover toda clase de actividades y prestar cuantos servicios públicos contribuyan a satisfacer las necesidades y aspiraciones de la comunidad vecinal» (art. 25, 1), pudiendo llevar a cabo - y la precisión es capital- «actividades complementarias de las de otras Administraciones públicas» (art. 28); aptitud de la que carece, desde luego, la Provincia, la cual, dada su condición de Corporación de Corporaciones o de simple agrupación de Municipios, no tiene otros fines propios y específicos $-\mathrm{y}$, por tanto, otra capacidad- que los de garantizar la solidaridad y el equilibrio intermunicipales (art. 31, 2) mediante la coordinación de los servicios de los Municipios y la prestación a éstos de la asis- 
tencia técnica, económica y jurídica que necesiten para el normal funcionamiento de sus propias actividades y servicios.

En segundo lugar, la LBRL incorpora a su articulado, como traducción concreta del genérico derecho de participación de los Municipios en la gestión de los asuntos públicos, una lista de quince grupos de actividades o materias en las que, por afectar sin ninguna duda a intereses vecinales, la propia LBRL dispone que el Municipio habrá de ejercitar competencias en todo caso, competencias cuya gradación y naturaleza concretas (exclusivas, compartidas, concurrentes, etc.) sólo a la Ley (y no a los Reglamentos) corresponde determinar (art. 25). Tampoco hay aquí paralelismo alguno con las Corporaciones provinciales, a las cuales no se garantiza un ámbito de materias propias, ni siquiera aquellas que, como la asistencia hospitalaria, la beneficencia o las carreteras, venían siendo actividades típicas de las Diputaciones provinciales.

Finalmente, en línea con la tradición legislativa de nuestro Régimen local, pero mejorando notablemente sus determinaciones, la LBRL da un paso más en esa misma dirección de singularización del contenido material de la autonomía municipal, al señalar cuáles son los servicios que, en función de su densidad demográfica, habrán de ser, como mínimo, prestados por cada Municipio, en solitario o en asociación con otros (art. 26), cuidándose la Ley de advertir que la constitución, en su caso, de Corporaciones territoriales más amplias de tipo comarcal no implicará merma alguna en la competencia municipal para seguir prestando tales servicios públicos mínimos, ni tampoco para intervenir en alguno de los quince grupos de materias o actividades a que antes hemos hecho referencia. Tampoco aquí hay, en rigor, analogía o paralelismo alguno con la posición de las Provincias, pues, aunque es cierto que la LBRL, en su artículo 36, 1, califica como competencia propia de aquéllas «la prestación de servicios públicos de carácter supramunicipal y, en su caso, supracomarcal», ello no puede significar en modo alguno que todos los servicios de carácter supramunicipal hayan de ser forzosamente gestionados a partir de ahora por las Diputaciones provinciales (una interpretación semejante chocaría abiertamente con lo que al respecto disponen la mayoría de los Estatutos de Autonomía), sino que lo serán sólo en la medida en que así lo digan las Leyes del Estado o de las Comunidades Autónomas.

La Provincia goza, en suma, de una autonomía de menor intensidad y alcance que la municipal, de una autonomía que podríamos 
calificar como autonomía de apoyo a los Municipios y que sólo en función de dicho apoyo tiene justificación. Por ello mismo, las Provincias son Entes de carácter esencialmente fungible o instrumental, que en determinadas Regiones o Nacionalidades gozan, es cierto, de una fuerte tradición y de un protagonismo indiscutible en la acción de los poderes públicos (Euskadi sería el ejemplo más patente de esta tradición), y que en tal sentido pueden servir de vehículos de gestión ordinaria de servicios propios o de funciones delegadas de las Comunidades Autónomas, como quiere la actual LBRL siguiendo las huellas trazadas por la Ley del Proceso Autonómico y por algunos Estatutos de Autonomía; pero no es menos cierto que en otras zonas del territorio nacional sus funciones serían sustituibles sin dificultad por otros tipos de Entes territoriales: piénsese, por ejemplo, en el supuesto emblemático de las Comunidades Autónomas uniprovinciales, en particular aquellas que carecen de "entidad regional histórica", como es el caso de Madrid, en las que la Provincia ha dejado de existir como tal Entidad local (aunque su desaparición comporte, ciertamente, el ascenso a un nivel superior de autonomía); o en las Comunidades Autónomas insulares, en las cuales la Isla se configura como Ente local intermedio entre el Municipio y la propia Comunidad Autónoma (pese a lo cual, en lo que concierne al Archipiélago canario, la LBRL procede sorprendentemente a "resucitar» las antiguas Mancomunidades provinciales interinsulares que el Estatuto de Autonomía había liquidado y sepultado, si bien la citada resurrección es más aparente que real, pues limita su cometido a la representación y expresión de los intereses provinciales, sin competencia funcional o material alguna); o, finalmente, en la pretensión de Cataluña, apoyada en hechos históricos incontestables, de sustituir las divisiones provinciales por otras de tipo comarcal más enraizadas en la realidad política y administrativa de aquella Comunidad Autónoma.

En conclusión: la «efectividad práctica» de la autonomía local no va a depender sólo de la recién estrenada Ley Básica del Régimen local. Carente de poderes taumatúrgicos, la nueva Ley no va a solucionar por sí sola los agobiantes problemas de las conurbaciones metropolitanas, ni a redimir a los abandonados Municipios rurales, ni a colmar los déficit de servicios y dotaciones colectivas en tantos y tantos Municipios, ni a llenar las vacías arcas de otras tantas Corporaciones vecinales, etc., pero sí va a permitir que los Municipios españoles actúen con la mayoría de edad y la responsabilidad que 
les reconoce y garantiza la Constitución. Hacia el logro de ese objetivo, más que en las bondades y aciertos de la Ley, que no son pocos, la efectividad del autogobierno local y su adecuado funcionamiento descansarán en el juego limpio de todas las partes implicadas, en la colaboración leal dentro de los límites del sistema autonómico y en el respeto recíproco de sus respectivas competencias. El éxito dependerá, a fin de cuentas, de la escrupulosa observancia de la directiva que se contiene en el artículo 10,1 , de la Ley (reiterada en el art. 55), y que dice así: «La Administración local y las demás Administraciones públicas ajustarán sus relaciones recíprocas a los deberes de información mutua, colaboración, coordinación y respeto a los ámbitos competenciales respectivos». 
REALA-1985, núm. 227. LEGUINA VILLA, JESUS. LA AUTONOMIA DE MUNICIPIOS Y PROVINC...

REALA-1985, núm. 227. LEGUINA VILLA, JESUS. LA AUTONOMIA DE MUNICIPIOS Y PROVINC... 